\title{
K-Ágora como possibilidade Geotecnológica para o entendimento de Espaço junto aos alunos do Ensino Fundamental I da Rede Pública da Cidade do Salvador/Bahia
}

\author{
Iury Barreto da Silva ${ }^{1}$, Tania Maria Hetkowski ${ }^{1}$, André Luiz Andrade Rezende ${ }^{1}$, \\ Josemeire Machado Dias ${ }^{1}$, Fabiana dos Santos Nascimento ${ }^{1}$, Andréa Ferreira \\ Lago ${ }^{1}$, Inaiá Pereira Brandão ${ }^{1}$ \\ ${ }^{1}$ Grupo de Pesquisa em Geotecnologias, Educação e Contemporaneidade \\ Universidade do Estado da Bahia (UNEB) - Salvador, BA - Brasil \\ \{iurybarreto, andre.luiz.rezende, josemeiredias, inaiabrandao18\} @gmail.com, \\ taniah@uneb.br, fabi30_nascimento@hotmail.com, brdea@yahoo.com.br
}

\begin{abstract}
The Information and Communication Technologies, especially the Geotechnologies might give an favor to understand of Space, supporting the cartographic notions and "geo-literacy" of the subjects. This proposal intend to present briefly, the methodological approach of the K-Ágora and its characteristics, that may permit the imagination, significance and dimensioning in the comprehension of geographic space, via simulation of the construction of a city, valuing the aspects that the child considers significant. As a results it will be presented the K-Ágora's functionalities, potentials (re/de)construction of day-to-day perspective to children, from the use by Applied Collaborative Methodology and methods PDCA and PDSII.
\end{abstract}

Resumo. As Tecnologias da Informação e Comunicação, em especial as Geotecnologias podem favorecer o entendimento de Espaço, auxiliando na apreensão de noções cartográficas e de "geo-letramento" dos sujeitos. Este artigo visa expor de forma breve, o percurso metodológico do K-Ágora e suas características, que podem possibilitar a (re)imaginação, (re)significação e (re)dimensionamento na compreensão de Espaço, pela simulação da construção de uma cidade, valorizando os aspectos que a criança considera significativos à sua vida. Como resultados serão expostos as funcionalidades do K-Ágora, potenciais a (reldes)construção do cotidiano dos alunos, a partir do uso da Metodologia Colaborativa Aplicada e dos métodos PDCA e PDSII.

\section{Introdução}

$\mathrm{Na}$ história da humanidade, o entendimento de Espaço $^{1}$ encontra-se presente no cotidiano dos sujeitos, mediando diferentes tipos de relação, desde as simples, como a brincadeira de caça ao tesouro, até as complexas, a exemplo das estratégias de guerra. Desse modo, percebe-se que essa dinâmica ocorre ao longo da vida, em várias situações distintas. Em consonância à afirmação anterior, temos Joly (1990), Francischett (2004) e Hetkowski et al. (2010), destacando que a relação do indivíduo com o Espaço acontece desde os primórdios, sem estar vinculada ao estágio de desenvolvimento da sociedade.

\footnotetext{
${ }^{1}$ Neste artigo, a inicial em maiúsculo da palavra Espaço ou a expressão "espaço geográfico" estão amparadas na perspectiva de Santos $(2006 ; 2008)$ e, referem-se ao "lugar" dos diferentes sujeitos, onde permeiam inúmeras instâncias, como: sociais, políticas, econômicas, culturais, técnicas, simbólica, de poder, entre outras.
} 
Diante disso, trazemos a Educação Cartográfica como a possibilidade de entrelaçamento entre o espaço geográfico e os saberes advindos dos espaços educativos, pautados na interlocução contínua entre sujeito e espaço.

No entanto, no transcorrer dos tempos, muitas instituições de ensino (públicas e privadas) abordam o estudo da cartografia, essencialmente, através da leitura/interpretação de cartas geográficas. Esse encaminhamento metodológico visualiza o Espaço de maneira fragmentada, trazendo uma concepção, na maioria das vezes, desvinculada da realidade. Argumenta-se que esse movimento estabelece uma lacuna no processo formativo das crianças, uma vez que entender o espaço geográfico, neste viés, é reforçar, exclusivamente, as técnicas de orientação, localização e interpretação das simbologias, sem permear o contexto e o próprio desenvolvimento ímpar de cada sujeito. Além disso, o cotidiano que se apresenta ao sujeito não encontra paridade ou semelhança nas linhas, áreas, cores e polígonos que estão presentes nos mapas, por consequência, perpetua o hiato, dentro e fora da escola.

Francischett (2004, p. 124) reforça a problemática, ao afirmar que "a maioria dos professores que trabalha com o ensino, concebem a Cartografia como a técnica de representar e ler mapas, desvinculada do contexto da Geografia". Talvez, por isso exista uma desvinculação entre o universo cartográfico e a dinâmica espacial do cotidiano, por parte de professores e alunos. Ou seja, existe uma dissonância entre o que é estabelecido nas cartas geográficas e o que vigora no locus. Essa lacuna reflete na impossibilidade, muitas vezes, em se estabelecer uma relação de pertencimento, quando da aproximação do indivíduo com os mapas.

De acordo com Schäffer (2003), ainda existem instituições de ensino alicerçadas na voz do professor e na passividade do aluno, sendo a construção do conhecimento conduzida exclusivamente pelo livro didático. Nessa estratégia, verifica-se que elementos com potencial didático-pedagógico, a exemplo das Tecnologias da Informação e Comunicação (TIC), são desconsiderados em sala de aula, devido ao desconhecimento por parte dos partícipes do processo educativo, assim como falta de estrutura física e material das escolas. Desse modo, conceber a Cartografia mediada por tais tecnologias, em especial, as Geotecnologias ${ }^{2}$, pode agregar valor ao processo formativo dos sujeitos, vez que, em certa medida, é possível simular os elementos e as relações cotidianas do Espaço.

Diante desse desafio, torna-se relevante pensar estratégias metodológicas alternativas e/ou criativas, com o objetivo de auxiliar os alunos sobre o entendimento de Espaço. Esse engendramento perpassa por um processo de letramento das tecnologias existentes para a compreensão do espaço geográfico. Nessa perspectiva, uma possibilidade que poderia despertar o interesse, o desejo e que potencialmente expandisse a compreensão sobre o espaço dos educandos são as Geotecnologias. Nessa perspectiva, articular noções cartográficas e o entendimento das dinâmicas socioespaciais pelos sujeitos através do artefato geotecnológico nomeado como $K$ Ágora $^{3}$, pode oportunizar diferentes processos formativos para professores e alunos nesse contexto.

\footnotetext{
${ }^{2} \mathrm{O}$ conceito em questão encontra-se amparado na aproximação de uma perspectiva tecnicista (ROSA, 2005; CÂMARA et al., 2004) e, avança para além, no sentido de extrapolar o viés instrumental, ampliando conceitualmente e demonstrando as possibilidades criativas. (BRITO; HETKOWSKI, 2010).

${ }^{3}$ Neste artigo, a expressão "artefato geotecnológico K-Ágora" poderá ser referenciada como K-Ágora.
} 
Assim, intenciona-se neste artigo, apresentar de forma breve, o percurso metodológico no desenvolvimento do K-Ágora e as características desse artefato geotecnológico, que podem possibilitar a (re)imaginação, (re)significação e (re)dimensionamento na compreensão do espaço geográfico, junto aos alunos do Ensino Fundamental I.

Este trabalho organizar-se-á em quatro (4) seções. A Introdução contextualiza a problemática relacionada ao entendimento de Espaço, trazendo autores que corroboram com a perspectiva conceitual defendida neste artigo. A descrição do arcabouço metodológico que alicerça o desenvolvimento do K-Ágora encontra-se na segunda seção. A apresentação dos resultados e as respectivas potencialidades do $K$-Agora estão na terceira seção. Após o tópico reservado à conclusão, são apresentadas as referências utilizadas.

\section{Métodos}

Antes de adentrar, de maneira aprofundada, na seção referente ao método deste trabalho, torna-se necessário contextualizar o percurso delineado da pesquisa que resultou neste texto. A intenção deste preâmbulo tem como objetivo fundante construir um encadeamento lógico, com vistas a subsidiar os encaminhamentos definidos no transcorrer deste tópico.

\subsection{Dos encontros formativos aos bits $e$ bytes: desvelando o processo de desenvolvimento do $K$-Ágora}

O Projeto $K$-Ágora ${ }^{4}$ fundamenta-se na Metodologia Colaborativa Aplicada, sendo definida pelo grupo de pesquisa em Geotecnologias, Educação e Contemporaneidade $\left(\right.$ GEOTEC $^{5}$ ) como: Colaborativa, por fomentar pesquisas de forma propositalmente coletiva, onde um conjunto de indivíduos possui a intencionalidade de interferir e sofrer interferência no/do coletivo; Aplicada, por gerar conhecimentos para aplicação e intervenção prática, dirigida à solução de problemas/objetivos específicos, que evoluem os sujeitos do saber e do fazer. No caso dessa pesquisa, personificado pelo artefato geotecnológico K-Ágora.

Assim, desde os momentos iniciais das práticas do Projeto K-Ágora, materializadas no âmbito da sala de aula pelos encontros formativos na escola (mapas, geotecnologias, trilhas, desenhos, jogos digitais/tabuleiros, entre outros), deu-se a produção de insumos técnicos/conceituais, de maneira colaborativa, através da participação dos alunos. Como exemplo, pode-se citar a obtenção dos elementos do espaço geográfico que estão presentes no cotidiano das crianças (Hospital, Rodoviária, Farmácia, etc.). Essa incursão possibilitou conceber e desenvolver o K-Ágora, a partir das necessidades vivenciadas pelos sujeitos, que, posteriormente, foram representadas nos desenhos das construções, ícones, funcionalidades, entre outros, conforme exibido na figura 1 .

\footnotetext{
${ }^{4}$ Neste artigo, o termo "Projeto K-Agora" refere-se ao conjunto de práticas colaborativas instituídas na escola, que intencionam a obtenção de insumos/necessidades, com vistas a gerar possibilidades (produtos/processos) que produzam mudanças no cotidiano dos sujeitos, a exemplo do artefato geotecnológico K-Ágora.

${ }^{5} \mathrm{O}$ grupo discute e propõe ações relacionadas ao ensino, pesquisa e extensão nos diversos níveis de formação, a respeito do entendimento de Espaço mediado pelas Tecnologias da Informação e Comunicação.
} 
V Congresso Brasileiro de Informática na Educação (CBIE 2016)

Anais do XXII Workshop de Informática na Escola (WIE 2016)

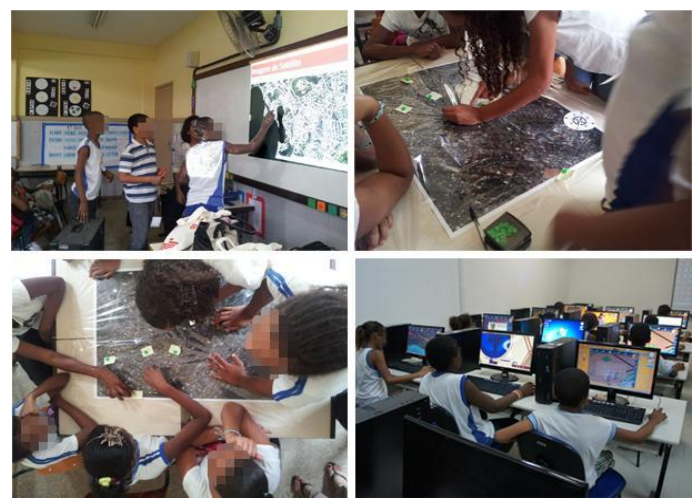

Figura 1 - Participação dos alunos nos encontros formativos do Projeto K-Ágora Fonte: Autores

Esse caminho inicia-se através das proposições (imaginação, desejo e real) dos alunos e dos pesquisadores do Projeto K-Ágora até resultar nos artefatos produzidos supracitados, mediante a constituição de um processo sistêmico (formado por equipes que se relacionam), cíclico (Escola - Universidade e vice-versa) e complementar (colaborativo, nas sugestões/críticas dos pesquisadores/alunos que operam diretamente no objeto em questão). Desse modo, têm-se a Escola, representada pelos alunos (diretamente), e a Universidade, personificada em seus pesquisadores, que se articulam como participantes ativos na materialização do $K$-Ágora. Isto é, ambos contribuem com informações que reverberam sobre a gênese do problema, neste caso, o entendimento de Espaço, sendo a obtenção dos dados operacionalizada, diretamente, no cotidiano dos partícipes.

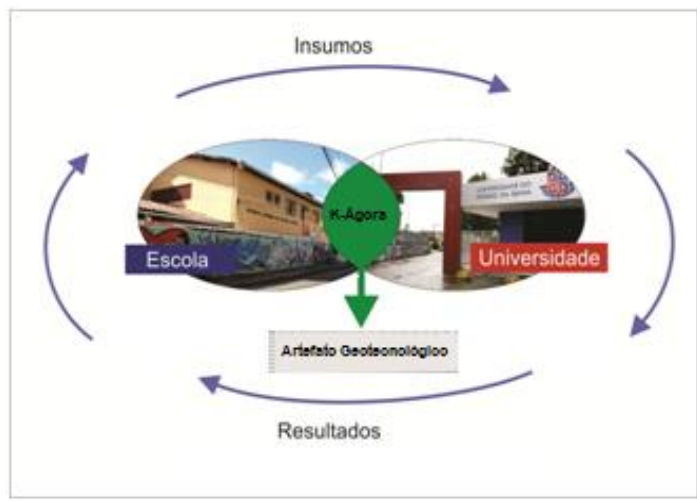

Figura 2 - Fluxo das informações relacionadas ao Projeto $K$-Ágora Fonte: Autores

Assim sendo, a dinâmica representada na figura 2, se apresenta como um movimento circular, composto por duas instâncias diferenciadas, que se coadunam no fito de operar/influenciar sobre as bases técnicas/conceituais possibilitando a (des/re)construção do artefato geotecnológico supracitado. É nesse universo que o fluxo cíclico se estabelece, ou seja, as informações oriundas da Escola fluem para a Universidade (Pesquisadores do Projeto), sendo consideradas como insumos conceituais. Posteriormente, dar-se-á o retorno à sala de aula, que se materializa através da aplicação de processos tecnológicos, sempre mediados por uma constante autocrítica entre as equipes. Esse resultado é encaminhado aos alunos, que, por consequência, tecem as respectivas considerações (sugestões/críticas), realimentando a pesquisa.

É nesse contexto que pesquisadores e alunos encontram-se imersos, buscando presenciar e interpretar o maior número de situações manifestadas no objeto central, 
neste caso, o artefato geotecnológico K-Ágora. As observações são interpretadas, tornando-se fundantes na geração de novos produtos, a exemplo das construções e/ou funcionalidades. Estes, por sua vez, retornam à sala de aula para novamente serem analisados (des/re/construir) e discutidos pelos alunos.

De forma resumida, a dinâmica estabelecida no Projeto K-Ágora subsidia a definição/realimentação dos requisitos e a sua respectiva verificação. Entretanto, o desdobramento técnico (bits e bytes) relativo ao artefato geotecnológico K-Ágora, darse-á por um conjunto de métodos adaptados: ciclo PDCA (Plan, Do, Check, Act) e o Processo de Desenvolvimento de Software Iterativo Incremental (PDSII). A adoção dos métodos supracitados, deu-se em virtude da aproximação da equipe técnica que compõe o Projeto K-Ágora. Destaca-se ainda que, devido às particularidades dessa pesquisa, algumas diretrizes de ambos os métodos foram modificadas, substituídas ou excluídas, tornando possível alcançar os objetivos propostos.

A combinação dos métodos PDCA e PDSII foi idealizada para o desenvolvimento do K-Ágora, em particular pela flexibilidade e foco na qualidade do produto final. Dessa forma, utilizou-se o PDCA para controlar o projeto de desenvolvimento na totalidade, ou seja, iniciando pelos requisitos coletados nas oficinas formativas até a conclusão do artefato geotecnológico supracitado. Em relação o PDSII (Concepção, Elaboração, Construção e Transição), utilizou-se, especificamente, para o gerenciamento dos aspectos técnicos (bits e bytes) relacionados ao K-Ágora. Desse modo, a junção desses dois métodos, está representada na tabela 1.

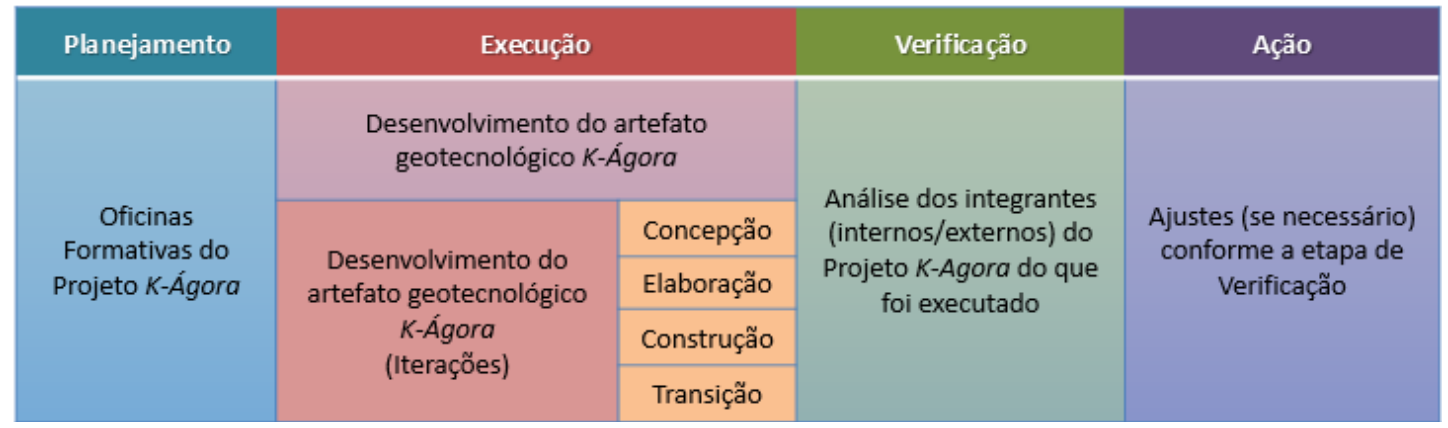

Tabela 1 - Fluxo das informações relacionadas ao desenvolvimento do artefato geotecnológico $\mathrm{K}$-Ágora

Fonte: Autores

Em continuidade a apresentação do processo de desenvolvimento do K-Ágora, temos no ciclo PDCA, a fase de verificação. A etapa em questão, materializa-se nas inúmeras práticas realizadas com os alunos, desde a escolha dos elementos (edificações) do espaço geográfico até os testes das funcionalidades produzidas. A título de exemplificação será relatado a execução de uma das oficinas formativas, cujo objetivo foi avaliar o potencial didático-pedagógico, em conformidade a um planejamento pedagógico predefinido.

No dia 17 de novembro de 2015, ocorreu um encontro de 40 minutos, contando com a presença de 30 alunos do $3^{\circ}$ ano do Ensino Fundamental I, na faixa etária variando de 08 a 12 anos, da Escola Municipal Álvaro da Franca Rocha, localizado no bairro da Engomadeira, na cidade de Salvador-Bahia. Imagens deste encontro podem ser visualizadas na Figura 3. Conforme o plano de atividades, foi solicitado aos alunos que criassem um mapa novo, a partir do endereço da escola, por meio da opção "Novo Mapa". Na sequência, solicitou-se a construção de uma Escola no Espaço onde se 
localiza a sua escola. A maior parte dos estudantes não identificou a instituição através do mapa, sendo necessária a intervenção da equipe pedagógica. A próxima atividade estava relacionada à identificação, por parte dos alunos, da própria residência e a inserção no mapa de uma construção semelhante à sua moradia.

Após reconhecer a própria moradia e a escola, foi solicitado a exploração das construções no mapa. Nessa atividade, buscou-se trabalhar com o Espaço percebido pelas crianças, o desejo e a imaginação, com intuito de modificarem o mesmo, inserindo elementos de desejo e interesse no bairro. Desta forma, padarias, sorveterias, lanchonetes e restaurantes se misturaram a shoppings, estádios de futebol, zoológicos e até mesmo praia, em plena região central da cidade.

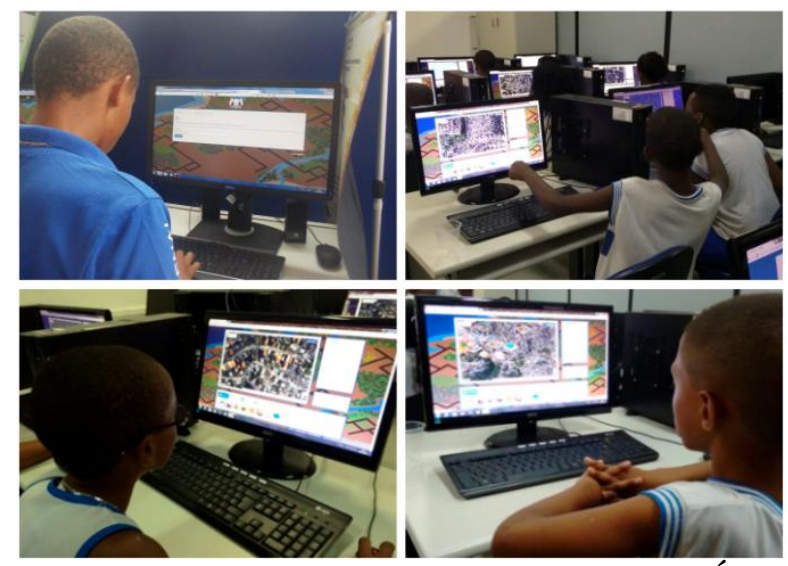

Figura 3 - Encontro para experimentação do K-Ágora Fonte: Autores

Outro exemplo a destacar é a atividade de experimentação da opção Carregar Mapa. Nesta dinâmica, foi solicitado aos estudantes que escolhessem um mapa de outro colega e discutissem sobre as diferenças entre as diversas percepções do Espaço. A atividade em questão, findou com outro momento de exploração do próprio mapa criado, desta vez, direcionado ao desejo, para inserção de construções que não existem naquela localidade.

Ao térmico do encontro, foram identificadas necessidades de melhorias, que posteriormente foram implementadas, como a criação de uma mensagem de confirmação no momento da exclusão das edificações, evitando a remoção acidental das construções. Ficou constatado que, por medida de segurança, a funcionalidade de exclusão de mapas deveria estar protegida com uma senha. Verificou-se também, a necessidade de salvamento automático, definido inicialmente a cada 5 minutos, para não depender da interação do aluno no salvamento do seu progresso. Ademais, a aproximação dos alunos com a ferramenta geotecnológica chamada Google Earth, evidenciou a necessidade de simular no K-Ágora a função Street View (percepção tridimensional do espaço) e, por fim foram sugeridas adaptações na funcionalidade de zoom in/out, de modo que as edificações não fossem visualizadas com proporções incorretas, acarretando também em imagens distorcidas.

Durante o encontro, percebeu-se o maior envolvimento quando a temática estava relacionada ao desejo, ou seja, a materialização no mapa de elementos inexistentes no contexto dos sujeitos. Alguns alunos externaram a sensação de controle e empoderamento, oportunizado pela possibilidade de (re)construir o próprio bairro a partir do seu olhar. Neste processo de (re)imaginação, algumas construções estiverem 
presentes na maioria dos mapas, desvelando um anseio por parte dos alunos, por espaços de lazer (praia, o estádio de futebol, a biblioteca, o zoológico e a sorveteria) no bairro onde residem. Os estudantes valorizaram a experiência no ambiente de uma universidade, e na expressão de um deles: "conhecer a tecnologia". Destacaram também, a funcionalidade referente ao compartilhamento de mapas do K-Ágora, com a oportunidade de visitar o Espaço criado por outros alunos e identificarem as diferenças de percepção do espaço geográfico compartilhado entre eles. Foi relatada a intenção de continuar a experiência em casa.

Esta dinâmica propicia uma realimentação contínua da pesquisa, de forma cíclica, gerando novos requisitos, que por sua vez retornarão ao ambiente da sala de aula para uma nova rodada de avaliações. Desta forma objetiva-se o aprimoramento contínuo da ferramenta, principalmente por basear-se nas necessidades do público-alvo, este formado por alunos da Educação Básica na faixa etária de 08 aos 12 anos, refletindo o envolvimento destes sujeitos no processo de desenvolvimento do K-Ágora, assim como nas descobertas e aprendizagens que o mesmo possibilita.

\section{Resultados e discussão}

A utilização de soluções computacionais e geotecnologias para auxiliar no ensino de conceitos de geografia e cartografia foram registrados em outros trabalhos científicos. Da Silva e Carneiro (2012), defendem o potencial adaptativo das geotecnologias como recurso didático, através do uso de imagens via satélite para reflexão dos alunos em questões de degradação ambiental. A importância da aplicação destas tecnologias em encontros formativos pode ser percebida em Martins, Seabra e Carvalho (2013), com a elaboração e execução de exercícios práticos construídos, a partir do uso de imagens de satélite do Google Earth, em uma turma do sexto ano do Ensino Fundamental II.

Nos anais WIE, SBIE e CBIE/WCBIE, encontramos Pereira e Teixeira (2011), que trabalham noções e conceitos de relevo com o auxílio de visualizações na ferramenta Google Earth e a pesquisa de Oliveira, Nascimento e Filho (2013), cujos alunos demarcavam na ferramenta Google Maps os pontos de maior degradação no distrito de Ponta da Serra - CE. Com o aplicativo Geomóvel, Marçal et al (2013), utilizavam anotações georeferenciada e o padrão KML para permitir a interoperabilidade dos mapas e marcações, uma das principais características do $K$-Ágora.

Assim como os trabalhos citados, este também se utiliza de ferramentas geotecnológicas com o objetivo de reconhecimento e mapeamento. Ressaltamos, que o diferencial do nosso projeto, se alicerça na construção coletiva, fruto dos desejos das crianças e materializados no K-Ágora, como os tipos de construções, ícones, interfaces, usabilidade entre outros. Ademais, o artefato possibilita, em certa medida, a simulação da construção de uma localidade, com foco nas dinâmicas socioespaciais e na relação de pertencimento do aluno, trazendo mapas que explorem o bairro onde estudam e/ou vivem, valorizando o conhecimento cartográfico a partir do reconhecimento de paisagens importante para eles, potencializando o engajamento dos estudantes através da utilização de mapas, onde seja possível perceber a relação direta com o seu cotidiano.

A construção coletiva do artefato geotecnológico originou-se desde os primeiros encontros formativos realizados pelo Projeto $K$-Ágora, onde a partir dos insumos e necessidades observadas, definiram-se algumas características fundantes ao software, dentre elas, destaca-se a possibilidade de intercambiar mapas entre as diversas aplicações 
Geotecnológicas, a exemplo do Google Maps ${ }^{6}$ e Google Earth ${ }^{7}$. Desse modo, a partir de bases existentes e de acesso público, seria disponibilizada aos professores e alunos uma maior diversidade de mapas, ampliando as formas de uso e possibilitando que o entendimento do Espaço, seja algo mais concreto no ambiente lúdico. Com a troca de conteúdo cartográfico, é possível ampliar as possibilidades de interação por parte dos educandos, permitindo, por exemplo, que os professores utilizem os mapas de sua cidade/bairro, numa simulação de planejamento e gestão urbana, justamente pelo potencial pedagógico.

Para tanto, tornou-se necessário que o K-Ágora suporte um padrão de comunicação entre as diversas plataformas Geotecnológicas, no intento de ampliar a interoperabilidade entre soluções computacionais. Assim, adotou-se a linguagem indicada pelo Open Geospatial Consortium ${ }^{8}$ (OGC) nomeada como Keyhole Markup Language (KML), que permite a manipulação de dados geográficos como geometria, latitude e longitude em um software geotecnológico com suporte a mapas bidimensionais e/ou tridimensionais.

Desta maneira, além da adoção do KML, permitindo o download, upload, compartilhamento, abertura e interpretação de mapas que sigam esta especificação, são também requisitos da ferramenta K-Ágora: permitir inserção e manipulação de novos elementos (construções) no mapa (divididos em 05 categorias: comércio, educação, habitações, infraestrutura e lazer); Possibilitar a utilização de ferramentas para operações geoespaciais como cálculo de área, distância entre dois pontos, identificação de coordenadas e cálculo de rotas; Oportunizar a criação de novos mapas, a partir de um endereço fornecido; Permitir diferentes modos de visualização e exploração do mapa, como satélite e terreno.

$\mathrm{Na}$ interface da página inicial do $K$-Ágora ${ }^{9}$, são exibidas 04 (quatro) abas (K-Ágora, Novo Mapa, Carregar Mapa e Créditos) que apresentam respectivamente: as concepções que fundamentam a solução computacional, a possibilidade de materializar qualquer mapa, a partir da descrição textual (texto livre) da localização desejada, a exploração/edição de mapas previamente pesquisados e, por fim, a equipe que participou do desenvolvimento.

$\mathrm{Na}$ figura 4 podem ser visualizados alguns dos elementos e telas que compõem o artefato. As opções Novo Mapa e Carregar Mapa (item 1 da Figura 4), permitem a criação de um mapa a partir de qualquer endereço de nosso planeta, ou o upload de um mapa gerado e modificado em outras aplicações com suporte a KML. No item 2 da Figura 4, podemos visualizar a interface para edição e experimentação dos mapas, onde os alunos podem explorar e modificar os mapas por meio da inserção de novas construções, independente delas de fato existirem ou não em determinada localidade, além da translação e alteração dos nomes das edificações, permitindo a (re)imaginação, (re)significação e (re)dimensionamento da compreensão de Espaço.

\footnotetext{
${ }^{6}$ Disponível em: <http://maps.google.com.br/>. Acesso em: 20 maio 2016.

${ }^{7}$ Disponível em: <http://www.google.com/intl/pt-PT/earth/index.html/>. Acesso em: 20 maio 2016.

${ }^{8}$ Organização internacional composta por mais de 280 instituições, governamentais, comerciais e acadêmicas, que visam o desenvolvimento e implementação de padrões relativos a conteúdos e informações geoespaciais.

${ }^{9}$ Disponível em: <https://kimera4.websiteseguro.com/kagora/>. Acesso em: 20 maio 2016.
} 

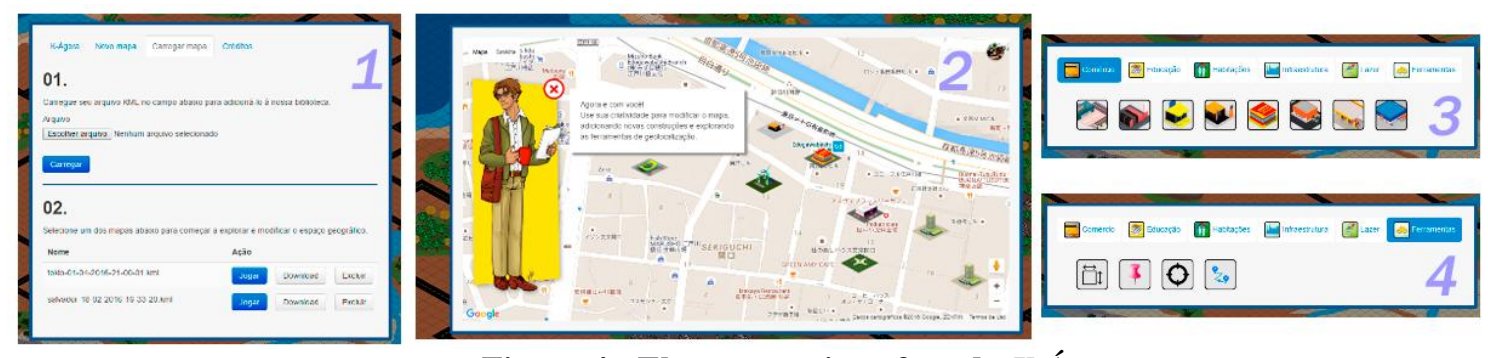

Figura 4 - Elementos e interface do K-Ágora Fonte: K-Ágora

Para promover atividades de leitura e escrita com os alunos, possibilitando trabalhar com letramento, foi adicionada ao $K$-Ágora a funcionalidade Cartas Voadoras, que possui duas finalidades distintas, a depender do perfil de acesso do usuário; comunicação instantânea ou registro de mensagens de texto. Esta funcionalidade consiste na abertura de um pop-up estilizado com um papel de carta com asas, sendo possível a digitação de textos neste espaço. Caso o usuário esteja autenticado com um perfil de administrador ou de docente, a mensagem contida na carta voadora será enviada para todos que estejam online naquele momento, funcionando como uma ferramenta de comunicação e orientação. Caso seja um aluno, o texto escrito na carta voadora será armazenado na forma de registro, para que o estudante possa efetuar as anotações que porventura achar interessantes ou necessárias (no caso de uma atividade orientada).

Ademais, tem-se as funcionalidades para operações geoespaciais (item 4 da Figura 4): medir área, medir distâncias, retornar coordenadas geográficas e calcular rota. Estas, por sua vez, permitem avançar na manipulação das construções e possibilitam a exploração de conteúdos referentes à cartografia e geometria plana, oportunizando a criação de atividades dirigidas, acerca do entendimento do espaço geográfico.

\section{Conclusões}

Diante das dificuldades no ensino de uma Cartografia que considere o contexto e o olhar dos sujeitos leitores sobre os diferentes mapas, percebemos que a ferramenta é potencial, e que as funcionalidades que a compõem, com base nos requisitos levantados a partir das necessidades pedagógicas fundantes deste projeto foram atendidas.

A utilização do padrão KML permitiu o armazenamento e a troca de mapas. A inclusão das ferramentas para operações geoespaciais e a manipulação de construções nos mapas, podem oportunizar a (re)imaginação, (re)significação e (re)dimensionamento do entendimento de Espaço. Desta forma, entendemos que uma proposição Geotecnológica, como o K-Ágora pode ser considerada como uma estratégia metodológica criativa.

Apesar de toda a aceitação que a ferramenta obteve junto aos docentes e discentes durantes as oficinas formativas, inclusive com os alunos que externaram o desejo de continuar a usar a ferramenta mesmo após o final dos encontros de testes, os autores deste projeto entendem que se faz necessário um rigor metodológico na avaliação do K-Ágora. Desse modo, como proposição de melhoria será realizada a avaliação do artefato geotecnológico baseada em perspectivas (Dias et al., 2013). De forma resumida, o método consiste em avaliar o $K$-Ágora, fundamentado em no mínimo 04 (quatro) "olhares diferenciados". Esta delimitação, intenciona obter informações direcionadas por especialistas de um determinado domínio. Desse modo, ao findar de 
V Congresso Brasileiro de Informática na Educação (CBIE 2016)

Anais do XXII Workshop de Informática na Escola (WIE 2016)

uma análise, as conclusões possuem um enfoque específico e aprofundado. Do contrário, teríamos avaliações que abordam inúmeras áreas do jogo, sem um foco definido.

\section{Referências}

Brito, F. J. O. e Hetkowski, T. M. (2010) "Geotecnologias: Possibilidades de Inclusão Sócio-Espacial" em: Inclusão sociodigital: da teoria à prática. 1. ed., v.1500, Curitiba.

Câmara, G., Monteiro, A. M. e Medeiros, J. S. (2004) "Introdução à Ciência da Geoinformação", INPE, São José dos Campos.

da Silva, F. G. e Carneiro, C. D. R. (2012). "Geotecnologias como recurso didático no Ensino de Geografia: Experiência com Google Earth". Caminhos de Geografia, V.13.

de Oliveira, M. T. L., do Nascimento, K. A. S. e de Castro Filho, J. A. (2013). "Os impactos ambientais da ponta serra registro das atividades com o auxílio do laptop educacional" em Anais dos Workshops do Congresso Brasileiro de Informática na Educação. Vol. 2, No. 1.

Dias, J. M. ; Nascimento, F.S. ; Hetkowski, T. M. ; Brandão, I. ; Pereira, T. R. D. S. . Avaliação de jogos educacionais digitais baseada em Perspectivas. Uma experiência através do Jogo-simulador Kimera. Anais do Simpósio Brasileiro de Jogos e Entretenimento Digital, v. 1, p. 1, 2013.

F. Shull, I. RUS, V.BASILI. How Perspective-Based Reading Can Improve Requirements Inspections, IEEE Computer, Vol. 33, No. 7, July 2000.

Francischett, M. N. (2004) "A Cartografia no ensino de Geografia: a aprendizagem mediada", Edunioeste, Cascavel.

Hetkowski, T. M. (2010) "Geotecnologia: como explorar educação cartográfica com as novas gerações?", Endipe, Belo Horizonte.

Joly, F. (1990) "A cartografia". Papirus, Campinas.

Marçal, E. et al. (2013). "Geomóvel: Um Aplicativo para Auxílio a Aulas de Campo de Geologia" em Anais do Simpósio Brasileiro de Informática na Educação.V. 24, p. 52.

Martins, L. J., Seabra, V. D. S. e Carvalho, V. S. G. D. (2013). "O uso do Google Earth como ferramenta no ensino básico da Geografia". Simpósio Brasileiro de Sensoriamento Remoto.

Pereira, A. M. D. O., e Teixeira, A. C. (2011). "As Tecnologias de Rede como Espaço de Aprendizagens Significativas em Geografia" em Anais do Workshop de Informática na Escola. Vol. 1, No. 1, pp. 1157-1167).

Rosa, R. (2005), "Geotecnologias na geografia aplicada" em: Revista do departamento de geografia, n. 16, p. 81-90, Uberlândia.

Santos, M. (2006) "A Natureza do Espaço: Técnica e Tempo, Razão e Emoção" 4. ed. Edusp, São Paulo. (2008) "Espaço e Método". 5. ed. Edusp, São Paulo.

Schäffer, N. O. et al. (2003) "Um globo em suas mãos: práticas para a sala de aula". UFRGS, Porto alegre. 